\title{
EVALUATION OF DIFLUBENZURON FOR PORINA CONTROL IN SOUTH OTAGO
}

\author{
C.M. FERGUSON ${ }^{1}$, G.W. KERSE ${ }^{2}$ and A.A. EVANS ${ }^{1}$ \\ ${ }^{1}$ AgResearch, Invermay Agricultural Centre, PB 50034, Mosgiel \\ ${ }^{2}$ Nufarm Ltd, PO Box 11-148, Christchurch
}

\begin{abstract}
Previous work assessing the suitability of using diflubenzuron for porina control in New Zealand has shown it to be effective in most areas of New Zealand, but results from the southern South Island have been inconsistent. Trials were conducted in South Otago in 1994, comparing two rates of diflubenzuron, and 1995, comparing diflubenzuron with chlorpyrifos. Diflubenzuron, applied at the manufacturers recommended rate, gave $78 \%$ and $80 \%$ control of porina in 1994 and $73 \%$ control in 1995. This compares with an average of $95 \%$ control achieved using chlorpyrifos in 1995. The results show that diflubenzuron can give significant levels of control of porina in South Otago and is a viable option for farmers.
\end{abstract}

Keywords: dimilin, diflubenzuron, porina, Wiseana sp.

\section{INTRODUCTION}

Porina, a complex of several Wiseana species (Lepidoptera: Hepialidae), are the major invertebrate pasture pests in the southern South Island (Barratt et al. 1991). Control of these pests, when it is attempted, is generally by insecticide application but conventional insecticides are regarded by farmers as expensive. A more cost effective approach to porina control is to use the insect moulting hormone diflubenzuron which prevents larvae moulting to the next instar. For the greatest economic response, diflubenzuron should be applied while caterpillars are small, and moulting frequently. Although large porina are killed by diflubenzuron, it takes longer for mortality to occur (Wrenn et al. 1985) and damage to pasture continues until mortality is effected. It is possible to predict which pastures are likely to be damaged by porina and an early warning technique to augment predictions is available (Barratt et al. 1991). This makes it possible to treat pastures in time to maximise porina mortality. The current cost of diflubenzuron ( $\$ 8.50 /$ ha excluding application costs) makes it an attractive control option to farmers. However despite diflubenzuron being used successfully in most areas of New Zealand, trials in the southern South Island have given inconsistent or low levels of control (Stewart and Ferguson 1989; Ferguson et al. 1989). The results of the trials reported here show that diflubenzuron can give satisfactory levels of porina control in the southern South Island.

\section{Field trials - 1994}

\section{METHODS}

In two trials (sites 1 and 2), near Owaka in South Otago, plots measuring $5 \mathrm{~m} \times 10 \mathrm{~m}$ were replicated four times in a randomised block design. Diflubenzuron (Dimilin $25 \mathrm{~W}$ ) was applied at rates of $12.5 \mathrm{~g} / \mathrm{ha}$ or $25 \mathrm{~g} / \mathrm{ha}$ using a precision knapsack sprayer and hand held boom in 240 litres water/ha on 4 April 1994. Untreated plots served as controls. Porina populations were estimated prior to application and at 8 and 13 weeks after treatment using the board technique (Barratt et al. 1991). On each occasion five $0.1 \mathrm{~m}^{2}$ boards /plot were laid out in the afternoon and porina burrows counted the following morning. 
The logarithms of porina counts were analysed by ANOVA. At site 1 the pretreatment counts were used as covariates in the analyses. Back transformed means are presented in Table 1.

\section{Field trials - 1995}

Porina densities and larval size were estimated at two sites (sites 3 and 4) near Owaka on 20 March 1995 by taking twenty 150 x 150 x 30 mm deep turves from each site. The porina larvae were extracted by placing inverted turves in Tulgren funnels fitted with $150 \mathrm{~W}$ light bulbs for 24 hours. At each site diflubenzuron $(12.5 \mathrm{~g} / \mathrm{ha})$ or chlorpyrifos (Lorsban 40 EC) (600 g/ha) were applied in 200 litres of water/ha on 27 March 1995. The 30 x 6 m plots were arranged in a randomised block. In each block, an untreated plot served as a control. There were three replicates at each site. Porina densities were estimated 4 weeks after insecticide application by digging twenty spade samples $(150 \times 150 \times 200 \mathrm{~mm}$ deep) from each plot. Porina were extracted from the top $30 \mathrm{~mm}$ of each sample by heat extraction as above, and from the remainder by hand sorting in the field. After 12 weeks, densities were estimated by counting porina burrows in twenty quadrats $(280 \times 320 \mathrm{~mm})$ per plot in a $50 \mathrm{~mm}$ deep flat bottomed trench made and lined with polythene sheeting 7 days previously (Kain et al. 1979).

The densities of larvae present in the turf above the polythene were measured by heat extraction of larvae, as described above, from ten sub-samples of cut turf $(100 \mathrm{x}$ $280 \times 50 \mathrm{~mm}$ deep ) per plot. The number of porina $/ \mathrm{m}^{2}$ given by heat extraction of the turves was added to the number of burrows $/ \mathrm{m}^{2}$ for each plot, to give an overall estimate of porina density.

The post treatment porina density data were analysed by generalised linear models using Poisson distributions and log links (Nelder and Wedderburn1972). The standard errors presented in Table 2 for site 3 on 27 April have been scaled by the square root of the residual deviance of the data to account for high variability. Other standard errors are not scaled.

\section{Field trials - 1994}

\section{RESULTS}

At the time of diflubenzuron application, the majority of caterpillars were between 25 and $35 \mathrm{~mm}$ long although individuals up to $50 \mathrm{~mm}$ long were occasionally found. No significant difference in numbers of porina burrows between plots was detected in the pre-treatment counts at site 1 . At both sites, significant reductions in porina numbers were associated with diflubenzuron application (Table 1). Eight weeks after treatment at site 1 , the average porina burrow density in plots treated with diflubenzuron at $12.5 \mathrm{~g} / \mathrm{ha}$ was reduced by $57 \%$ relative to the control plots and by $60 \%$ in plots treated with $25 \mathrm{~g} / \mathrm{ha}$ of diflubenzuron (both $\mathrm{P}<0.05$ ) (Table 1). After 13 weeks, these levels had increased to $68 \%$ and $79 \%$ respectively (both $\mathrm{P}<0.01$ ) (Table 1 ). At site 2 , the average porina densities in the diflubenzuron treated plots had decreased significantly by $71 \%$ and $76 \%$ (low and high rates respectively) relative to the control plots after eight weeks $(\mathrm{P}<0.01)$, and by $80 \%$ and $84 \%$ respectively after 13 weeks $(\mathrm{P}<0.01)$ (Table 1$)$. No significant differences in porina densities associated with the different rates of diflubenzuron were detected at either site (Table 1).

TABLE 1: Porina burrows $/ \mathrm{m}^{2}(\log$ transformed $) 8$ and 13 weeks after insecticide application.

\begin{tabular}{rrrcrr}
\hline & & Control & $\begin{array}{c}\text { Diflubenzuron } \\
(12.5 \mathrm{~g} \text { ai/ha) }\end{array}$ & $\begin{array}{r}\text { Diflubenzuron } \\
(25 \mathrm{~g} \text { ai/ha })\end{array}$ & SED \\
\hline Site 1 & 8 weeks & $40(3.68)$ & $17(2.81)$ & $16(2.78)$ & $(0.282)$ \\
& 13 weeks & $34(3.53)$ & $11(2.40)$ & $7(1.97)$ & $(0.268)$ \\
Site 2 & 8 weeks & $49(3.89)$ & $14(2.65)$ & $12(2.48)$ & $(0.321)$ \\
& 13 weeks & $44(3.79)$ & $9(2.25)$ & $7(1.94)$ & $(0.308)$ \\
\hline
\end{tabular}




\section{Field trials - 1995}

The mean length of larvae collected from both sites on 27 March 1996 was $26 \mathrm{~mm}$ $(\mathrm{SEM}=1.8)$ with no significant differences between the sites. At site 3, porina density immediately prior to insecticide application was estimated at $31 / \mathrm{m}^{2}(\mathrm{SEM}=10)$ but increased densities measured in the control plots subsequently (Table 2) suggests that many porina were missed during the initial and second samplings. At site 3 , four weeks after treatment there were no significant differences in average porina densities between the control plots and plots treated with diflubenzuron (Table 2) but densities in the chlorpyrifos treatment were reduced by $98 \%$ relative to both treatments $(\mathrm{P}<0.01)$ (Table 2). After 12 weeks average porina density in the diflubenzuron treated plots was reduced by $69 \%$ relative to the control plots $(\mathrm{P}<0.01)$ (Table 2$)$. Porina numbers in the chlorpyrifos treated plots at the same time were $92 \%$ lower than those in the control plots (Table 2) and were significantly lower than in the diflubenzuron treated plots $(\mathrm{P}<0.01)($ Table 2$)$. Pre-treatment porina density at site 4 was $73 / \mathrm{m}^{2}$ $(\mathrm{SEM}=25)$. Four weeks after treatment at this site, porina numbers were significantly lower in both the diflubenzuron and chlorpyrifos treated plots than in the control plots (55\% and $96 \%$ reductions relative to the control plots respectively) $(\mathrm{P}<0.01)$ (Table 2 ). The difference between porina densities in the diflubenzuron and chlorpyrifos plots was also significant $(\mathrm{P}<0.01)($ Table 2$)$. These differences were still apparent 12 weeks after treatment by which time the level of porina control associated with diflubenzuron had increased to $73 \%$ relative to the control plots $(\mathrm{P}<0.01)$ (Table 2) but was still significantly less than that associated with chlorpyrifos application $(97 \%)(\mathrm{P}<0.01)$.

\section{TABLE 2: Porina numbers/m² (SEM) 4 and 12 weeks after insecticide application.}

\begin{tabular}{rrccc}
\hline & Control & $\begin{array}{c}\text { Diflubenzuron } \\
(12.5 \mathrm{~g} \text { ai/ha })\end{array}$ & $\begin{array}{c}\text { Chlorpyrifos } \\
(600 \mathrm{~g} \text { ai/ha })\end{array}$ \\
\hline Site 3 & 4 weeks & $53(9)$ & $44(9)$ & $1(1)$ \\
& 12 weeks & $91(6)$ & $28(3)$ & $7(2)$ \\
Site 4 & 4 weeks & $66(5)$ & $30(3)$ & $3(1)$ \\
& 12 weeks & $63(5)$ & $17(2)$ & $2(1)$ \\
\hline
\end{tabular}

\section{DISCUSSION}

In both experiments, diflubenzuron was applied when the porina larvae were small and moulting frequently. This may have contributed to the high levels of mortality associated with the use of the moulting hormone as Wrenn et al. (1985) found small porina were more rapidly killed than larger porina in bioassays. With increasing larval size at the time of treatment, and longer periods between moults, mortality consequently takes longer to occur. This would explain why some mortality continued to occur between post-treatment assessments in both experiments. When two rates of diflubenzuron were used in 1994, no advantage was gained by increasing the amount of product applied over the manufacturers recommended rate of $12.5 \mathrm{~g} / \mathrm{ha}$. In both 1994 and 1995, the diflubenzuron was applied to short (50-75 $\mathrm{mm}$ high) pasture (although at site 2 clumps of cocksfoot were up to $150 \mathrm{~mm}$ high) and it is likely that good penetration and coverage of the vegetation by the spray contributed to the high levels of mortality achieved. In 1995 chlorpyrifos gave very high levels of control and this was probably also partly attributable to the low pasture height. Although in these trials chlorpyrifos was associated with significantly greater mortality of porina than diflubenzuron, the levels of control obtained by diflubenzuron clearly indicate it has a role to play in cost-effective porina control. The experiments did not provide any direct indication as to why diflubenzuron performed better than it did in previous trials in the southern South Island (Stewart and Ferguson 1989; Ferguson et al. 1989). Several species of porina co-exist in pasture in the region (Dugdale 1994) and it has been suggested that this may in some way affect the efficacy of diflubenzuron 
(Ferguson et al. 1989). Given the wide range of insects that are susceptible to diflubenzuron (Wearing and Thomas 1978; Frampton et al. 1987; Addison et al. 1992), efficacy is unlikely to be directly associated with porina species, but may be a function of the climatic and environmental factors that allow one or other porina species to dominate in any one season or location. This area needs further investigation.

\section{CONCLUSION}

Diflubenzuron application at the recommended rate of $12.5 \mathrm{~g} / \mathrm{ha}$ was shown to be an effective method of porina control in South Otago. Doubling the application rate did not affect the level of porina mortality achieved. Although diflubenzuron did not give as high levels of control as chlorpyrifos when compared directly with it, the levels achieved were high enough to warrant its recommendation as a cost-effective control agent for porina.

\section{ACKNOWLEDGEMENTS}

The authors would like to thank Mr. P.D. Johnstone for the statistical analyses of the data and the farmers, John Burgess, Barry Burgess, Alan Burgess, Brett Burgess and John Latta, for providing trial sites and assistance. This work was jointly funded by the Foundation for Science, Research and Technology and Nufarm Ltd.

\section{REFERENCES}

Addison, P.J., Firth, A.C. and Cliffe, A. 1992. The effects of diflubenzuron on lucerne flea. Proc. N.Z. Weed and Pest Control Conf. 45: 197-200.

Barratt, B.I.P., van Toor, R.F., Ferguson, C.M. and Stewart, K.M. 1991. Grass Grub and Porina in Otago and Southland: A Guide to Management and Control. MAFTechnology, Invermay Agricultural Centre, Private Bag, Mosgiel. 104pp.

Dugdale, J.S. 1994. Fauna of New Zealand. Ko te Aitanga Pepeke o Aotearoa. Number 30. Hepialidae (Insecta : Hepialidae). Manaaki Whenua Press. 164pp.

Ferguson, C.M., Jones, P.A. and Barratt, B.I.P., 1989. Diflubenzuron for porina control in Otago. Proc. N.Z. Weed and Pest Control Conf. 42: 71-72.

Frampton, E.R., Kerse, G.W. and Goldson, S.L. 1987. The effect of diflubenzuron on sitona weevil and its parasitoid, Microctonus aethiopoides. Proc. N.Z. Weed and Pest Control Conf. 40: 216-218.

Kain, W.M., Holland, T.V. and Atkinson, D.S.. 1979. Rapid methods for sampling soil-inhabiting insect pests of pasture. Proc. 2nd Aust. Conf. Grassl. Invert. Ecol.: 108-112.

Nelder, J.A. and Wedderburn, R.W.M., 1972. Generalised linear models. J. Roy. Stat. Soc. A. 135: 370-384.

Stewart, K M and Ferguson, C.M. 1989. Chemical control of porina in South Otago sheep pastures. N.Z. J. Agric. Res. 32: 395-400.

Wearing, C.H. and Thomas, W.P. 1978. Integrated control of apple pests in New Zealand. 13. selective insect control using diflubenzuron andBacillus thuringensis. Proc. N.Z. Weed and Pest Control Conf. 31: 221-228.

Wrenn, N.R., McGhie, R.A. and Pottinger, R.P. 1985. Bioassay and field experiments for evaluation of difluron for porina caterpillar control in pasture. Proc. 4th Aust. Conf. Grassl. Invert. Ecol.: 286-292. 